Coral Reefs (DOI 10.1007/s00338-017-1570-0)

\title{
Reef-fish larval dispersal patterns validate no-take marine reserve network connectivity that links human communities
}

Received: 7 September 2016 / Accepted: 14 March 2017

Rene A. Abesamis ${ }^{1,2, *}$, Pablo Saenz-Agudelo ${ }^{3}$, Michael L. Berumen ${ }^{4}$, Michael Bode ${ }^{5}$, Claro Renato L. Jadloc ${ }^{6}$, Leilani A. Solera ${ }^{7}$, Cesar L. Villanoy ${ }^{7}$, Lawrence Patrick C. Bernardo ${ }^{8}$, Angel C. Alcala ${ }^{2}$, Garry R. Russ ${ }^{1}$

${ }^{1}$ College of Science and Engineering/ARC Centre of Excellence for Coral Reef Studies, James Cook University, Townsville, Australia

${ }^{2}$ Silliman University-Angelo King Center for Research and Environmental Management (SUAKCREM), Dumaguete City, Philippines

${ }^{3}$ Instituto de Ciencias Ambientales y Evolutivas, Universidad Austral de Chile, Valdivia, Chile

${ }^{4}$ Red Sea Research Center, Division of Biological and Environmental Sciences and Engineering, King Abdullah University of Science and Technology, Thuwal, Kingdom of Saudi Arabia

${ }^{5}$ ARC Centre of Excellence for Environmental Decisions, School of Botany, University of Melbourne, Melbourne, Australia

${ }^{6}$ Silliman University-Institute of Environmental and Marine Science, Dumaguete City, Philippines 
${ }^{7}$ The Marine Science Institute, University of the Philippines-Diliman, Quezon City, Philippines

${ }^{8}$ Nadaoka Lab, Graduate School of Science and Engineering, Tokyo Institute of Technology, O-okayama Meguro-ku, Tokyo, Japan

*Communicating author: rene.abesamis@gmail.com; Telefax: +63 355220517

Keywords: Community fisheries; Coral Triangle; Marine protected areas; Network persistence; Recruitment subsidy 


\section{Abstract}

Networks of no-take marine reserves (NTMRs) are a widely advocated strategy for managing coral reefs. However, uncertainty about the strength of population connectivity between individual reefs and NTMRs through larval dispersal remains a major obstacle to effective network design. In this study, larval dispersal among NTMRs and fishing grounds in the Philippines was inferred by conducting genetic parentage analysis on a coral-reef fish (Chaetodon vagabundus). Adult and juvenile fish were sampled intensively in an area encompassing approximately $90 \mathrm{~km}$ of coastline. Thirty-seven true parent-offspring pairs were accepted after screening 1978 juveniles against 1387 adults. The data showed all types of dispersal connections that may occur in NTMR networks, with assignments suggesting connectivity among NTMRs and fishing grounds $(n=35)$ far outnumbering those indicating self-recruitment $(n=2)$. Critically, half $(51 \%)$ of the inferred occurrences of larval dispersal linked reefs managed by separate, independent municipalities and constituent villages, emphasising the need for nested collaborative management arrangements across management units to sustain NTMR networks. Larval dispersal appeared to be influenced by wind-driven seasonal reversals in the direction of surface currents. The best-fit larval dispersal kernel estimated from the parentage data predicted that $50 \%$ of larvae originating from a population would attempt to settle within $33 \mathrm{~km}$, and $95 \%$ within $83 \mathrm{~km}$. Mean larval dispersal distance was estimated to be $36.5 \mathrm{~km}$. These results suggest that creating a network of closely spaced (less than a few tens of km apart) NTMRs can enhance recruitment for protected and fished populations throughout the NTMR network. The findings underscore major challenges for regional coral-reef management initiatives that must be addressed with priority: (1) strengthening management of NTMR networks across political or customary boundaries; and (2) achieving adequate population connectivity via larval dispersal to sustain reef-fish populations within these networks. 


\section{Introduction}

Networks of no-take marine reserves (NTMRs) are systems of sea areas closed to fishing that have become a cornerstone of strategies to reverse declines in biodiversity and fisheries on coral reefs (McCook et al. 2009; Gaines et al. 2010). A fundamental ecological motivation for planning NTMRs as networks is connectivity, defined here as the linking of local populations through the dispersal of individuals during their pelagic larval phase and subsequent recruitment to recipient populations as juveniles and eventually as adults (Sale et al. 2005). In theory, connectivity among NTMRs and fishing grounds can promote synergistic population recovery and enhance fisheries by boosting recruitment to both protected and fished populations within a network (Gaines et al. 2010; Grorud-Colvert et al. 2014). However, the recruitment subsidy effect of NTMRs is still open to question (Pelc et al. 2010; Grorud-Colvert et al. 2014). The spatial and temporal variability of larval dispersal remain a considerable source of uncertainty in designing NTMR networks (Botsford et al. 2001; White et al. 2010; Burgess et al. 2014). To date, few studies have demonstrated both spatial and temporal patterns of larval dispersal within NTMR networks (e.g., Berumen et al. 2012; Cook et al. 2014).

Coral-reef fish are a rapidly diminishing source of food and livelihood for tens of millions of people living mostly in developing countries (Newton et al. 2007), and there is global interest in implementing NTMR networks on coral reefs (Mora et al. 2006; McCook et al. 2009). Consequently, reef fish are a major focus of research to define larval dispersal kernels (the probability of larvae settling at different distances from a source population) (Jones et al. 2009; Green et al. 2015). Research in the past two decades suggests that reef-fish larvae have a high probability of returning to their natal reef and that local populations are likely to be strongly linked by larval dispersal occurring within a few tens of km (Jones et al. 2009; 
Pinsky et al. 2010; Harrison et al. 2012; D'Aloia et al. 2015). Larvae recruiting back to their natal population and shorter-range larval dispersal may therefore be important in sustaining reef-fish populations (Steneck et al. 2009). In contrast, the demographic contribution of longer-range larval dispersal (hundreds of $\mathrm{km}$ ) is less understood (Williamson et al. 2016). However, the relative importance of local larval production versus connectivity in sustaining populations will depend on the size and spacing of habitats and their relationship with the spatial extent of larval dispersal (Botsford et al. 2001; Pinsky et al. 2012). For example, population replenishment may be dominated by connectivity as opposed to self-seeding (i.e., populations are more open than closed) in regions where the size of reefs and the distances between them are small relative to potential larval dispersal (Saenz-Agudelo et al. 2011; Pinsky et al. 2012). On the other hand, much less rigorous information is available showing how agents of larval transport or retention, such as wind, directional currents and eddies, influence reef-fish larval dispersal and therefore the potential distribution of recruitment subsidies from NTMRs (Saenz-Agudelo et al. 2012; Pusack et al. 2014).

There is growing international advocacy to create large-scale NTMR networks in developing nations, particularly in the highly threatened Coral Triangle region (Weeks et al. 2014; White et al. 2014). However, knowledge on how to design NTMR networks that are appropriate to the context of these countries is still at a nascent stage (McCook et al. 2009; Ban et al. 2011). Developing nations have characteristic social and geographic conditions that may limit the applicability of NTMR network design principles that mostly originate from the developed world (Ban et al. 2011; Green et al. 2015). Governance, customary tenure systems and protective management of coral reefs in developing countries can be finely structured at spatial scales smaller than the probable extent of ecologically relevant larval dispersal in reef fish (Weeks et al. 2010; Almany et al. 2013). While the distinctive setting of developing coral-reef nations already suggests that NTMR networks will require cooperation across 
political or customary stewardship boundaries (Green et al. 2009; Horigue et al. 2012), empirical studies on larval dispersal in this setting are lacking but essential to provide an ecological justification for cooperation, verify emerging network design principles and elucidate how recruitment subsidies (and therefore the costs and benefits of management decisions) may be distributed among network stakeholders.

Here, spatial and seasonal patterns of reef-fish larval dispersal were determined in a region of the central Philippines where numerous small-scale NTMRs have been established by coastal communities. Reef habitats in this region tend to be small and closely spaced and transport of larvae may be considerable due to a strong surface current and prevailing winds. Larval dispersal was inferred by conducting large-scale sampling and genetic parentage analysis on one species of reef fish (Chaetodon vagabundus). The study focused on three questions. (1) Would parentage assignments be dominated by inferred incidences of larval dispersal suggesting connectivity among village-based NTMRs and fishing grounds in separate municipalities, or dominated by inferred incidences of self-recruitment occurring at the scale of individual NTMRs or reefs? (2) How would larval dispersal differ seasonally given winddriven shifts in the direction of surface currents? (3) What is the shape of the potential larval dispersal kernel?

\section{Materials and methods}

\section{Geographic setting}

The study area encompassed the reef surrounding the Apo Island marine protected area (a national MPA) and 25 inshore fringing reefs ( 0.3 to $3.5 \mathrm{~km}$ long) situated along the southern coast of Negros Island (Fig. 1a). Jurisdiction over these reefs is divided among eight municipalities (Siaton, Zamboanguita, Dauin, Bacong, Dumaguete, Sibulan, San Jose and Amlan; Fig. 1a). The mean $( \pm \mathrm{SD})$ nearest-neighbour (centroid to centroid) distance between 
reefs was $3.9 \pm 3.0 \mathrm{~km}$ (range 1.4-11.5 km). A strong current, the Bohol Jet, flows yearround towards the west/southwest in the vicinity of Apo and southern Negros (Gordon et al. 2011) (Fig. 1b). The general direction of surface currents in the area can be affected by the seasonal reversal of prevailing winds in response to tropical heating (Wang et al. 2012), which are known in Southeast Asia as the southwest monsoon (southwesterly, usually from June to September) and the northeast monsoon (northeasterly, usually from November to March) (Wyrtki 1961). Monsoon-driven flow reversals were partially confirmed by obtaining vertical profiles of currents (surface to $100 \mathrm{~m}$ deep) in the study area using a $300 \mathrm{KHz}$ acoustic Doppler current profiler mounted on the side of a boat (Electronic Supplementary Material, ESM, Fig. S1). Currents were surveyed during two monsoon transition periods (May 2012 and May-June 2013) when weaker easterly winds prevailed, and once during the southwest monsoon (late September-early October 2012). Surveys could not be conducted during the northeast monsoon due to inclement weather.

\section{Management setting}

Reef-fish stocks in the central Philippines are subject to heavy fishing pressure due to high human population density and weak adoption or enforcement of more conventional fisheries management measures such as effort and catch restrictions (Nañola et al. 2011). However, NTMRs have become a socially accepted approach to reef management in this region and the idea of "scaling up" to NTMR networks is gaining traction (Alcala and Russ 2006; Lowry et al. 2009). Within the study area, 23 NTMRs (22 along the Negros coast and one within the Apo MPA) have been established at different times since 1982 by fishing communities (villages or barangay) without the intention of creating an inter-municipal network (Fig. 1a). The largest of these NTMRs has an area of $0.76 \mathrm{~km}^{2}$ (mean \pm SD: $0.10 \pm 0.15 \mathrm{~km}^{2}$ ). The mean nearest-neighbour distance between NTMRs was $3.0 \pm 2.7 \mathrm{~km}$ (range 0.6-11.6 km) while the farthest in-water distance between two NTMRs was approximately $75 \mathrm{~km}$. 
Collectively, the NTMRs protect $<1 \%$ of total reef area. Day-to-day management of the NTMRs in Negros is implemented at the village level with support from the local municipality. The NTMR and greater fished MPA at Apo are co-managed by the resident community, the municipality of Dauin and the Department of Environment and Natural Resources. Apo NTMR has been strictly protected since 1982 and has shown a steady buildup of target fish biomass over decades (Russ and Alcala 2010).

\section{Study species}

Chaetodon vagabundus (vagabond butterflyfish, Family Chaetodontidae) has a pelagic larval duration (PLD) of about 3 to 4 weeks (Leahy et al. 2015), similar to a wide range of reef-fish species in the Indo-Pacific (Lester and Ruttenberg 2005). Adults of the species are territorial mid-water spawners that form strong pair bonds (Tanaka 1992). The juveniles recruit in intertidal and shallow reef habitats before migrating to deeper reef habitats as they mature (Pratchett et al. 2008). These general reproductive and ontogenetic characteristics are more similar to larger reef-fish taxa that are common targets of fisheries (e.g., snappers, parrotfishes) as opposed to smaller and more site-attached species (e.g., damselfishes) (Thresher 1984; Honda et al. 2013). However, C. vagabundus is not a major fishery species, which may be disadvantageous for demonstrating the potential effects of NTMRs on fisheries but could be advantageous for gaining insights into patterns of larval dispersal that are less affected by fishing (through the alteration of demographic structure, reproductive behaviour, etc.). The use of exploited fish species for this study was less feasible because they tend to be rare outside NTMRs due to heavy fishing pressure.

\section{Large-scale sampling}

Adults and juveniles of $C$. vagabundus were sampled intensively but unevenly in 26 sites that spanned approximately $90 \mathrm{~km}$ of coastline: the reef surrounding Apo Island and the 25 
inshore reefs along the Negros coast (Fig. 1a). Adult population size in the study area was approximated by estimating mean $( \pm \mathrm{SD})$ adult density from transect surveys and extrapolating over the approximate total reef area (ESM, Table S1). Researchers and local fishers captured 1478 adults and 2071 juveniles using nets and spears and recorded the dates and sites of capture (see ESM, Supplementary Methods). A small tissue sample (dorsal fin clip $\sim 1 \mathrm{~cm}^{2}$ ) was obtained from each fish. Tissue samples were preserved in $95 \%$ ethanol and brought to the laboratory for genetic analysis (see below). Most juvenile fish were euthanised and collected for extraction and examination of sagittal otoliths to estimate PLD and date of spawning to infer seasonal larval dispersal patterns (see below). Very few samples were collected in the three northernmost sampling sites (Fig. 1a) because fish there were less abundant and very evasive. Sampling was not done inside NTMRs as this could cause misunderstanding with some stakeholders despite an extensive information and education campaign prior to sampling and municipal councils approving the research. The only justifiable way to deal with this limitation was to sample as close as possible to the boundaries of NTMRs, usually within tens of meters. A parentage assignment was considered to indicate larval dispersal between two NTMRs or between an NTMR and a fished area if the parent/s and/or offspring were sampled not more than $0.6 \mathrm{~km}$ from the NTMR/s in question, on the same reef as the NTMR/s. This distance is equivalent to the greatest linear dimension of the NTMRs. On the other hand, a parentage assignment would indicate selfrecruitment if an assigned juvenile was sampled on the same reef as its parent/s. Sampling was conducted from September 2011 to November 2012.

\section{Genetic parentage analysis}

DNA was extracted from each tissue sample and genotyped with a panel of 20 polymorphic microsatellite loci (ESM, Table S2). About 95\% of the samples (1387 adults and 1978 juveniles) were successfully amplified by PCR for at least 17 of the 20 loci. One of the 20 
loci (locus D8) showed significant departures from Hardy-Weinberg equilibrium and had to be excluded to avoid violating the assumptions of the parentage assignment method. None of the locus pairwise comparisons showed evidence of significant linkage disequilibrium.

Parent-offspring relationships were determined based on a maximum likelihood approach in the software FAMOZ (Gerber et al. 2003). FAMOZ provides results similar to other parentage assignment methods when 20 or more microsatellites are used (Harrison et al. 2013). The cumulative exclusion probabilities were 0.99999 and 1.0 for single parents and parent couples, respectively, when 19 loci (locus D8 excluded) were used. In turn, cumulative probabilities of identity (i.e., two individuals share the same genotype by chance) were low: $3.6 \times 10^{-27}$ for unrelated individuals and $3.1 \times 10^{-9}$ for sibs. FAMOZ computes log of the odds ratio (LOD) scores for parent-offspring relationships and constructs statistical tests for parentage assignments. These tests are based on the simulation of offspring from genotyped parents (true pairs) and from allele frequencies estimated from the genetic dataset (false pairs). Ten thousand offspring were simulated from true and false pairs. An error rate of $0.01 \%$ was incorporated to the simulation to take into account genotyping error while minimizing statistical errors associated with parentage tests. Genotyping error per locus ranged from 0 to $2.6 \%$. Genotyping error across all loci was $0.016 \%$ (ESM, Table S2). Minimum LOD score thresholds for accepting single-parent and two-parent assignments as being true were defined as the intersection between the two distributions of LOD scores from simulated offspring (true versus false pairs). LOD score threshold values were 5.1 for singleparent assignments and 18.0 for two-parent assignments. This parameter set was evaluated using the 'parentage test simulation' option in FAMOZ to estimate the probability of excluding a true parent knowing that it was in the sample (type I error) and the probability of assigning a false parent knowing that the true parent was not sampled (type II error). Type I and II errors for accepting parent-offspring assignments as being true with an LOD score 
threshold of 5.1 and an LOD error rate of $0.01 \%$ were estimated to be $0.02 \%$ and $1.64 \%$, respectively.

Despite the high exclusion probabilities and low type I and II errors, type II error (assigning a parent when the true parent was not sampled) was more likely than type I error because the percentage of potential parents sampled was relatively low (19.6\%, see Results) and the sampling of juveniles was not exhaustive. As a conservative measure to reduce false assignments associated with type II error, 35 single-parent assignments that had LOD scores higher than 5.1 but had confirmed mismatches (samples were re-scored and re-genotyped) between the genotype of the offspring and the genotype of the assigned parents at more than two loci were excluded. Larval dispersal distance was estimated for every accepted parentoffspring match by measuring the shortest in-water distance between the sites of capture of the parent fish and the offspring fish.

\section{Analysis of otoliths}

Transverse cross-sections of the left sagittal otoliths of juvenile fish in the accepted parentage assignments were prepared and interpreted as per Leahy et al. (2015). PLD was estimated by counting the daily rings between the centrum and the settlement mark and adding one day to approximate the duration of the egg stage in butterflyfish (Leis 1989). Post-settlement age was estimated by counting the daily rings between the settlement mark and the outer edge of the otolith. The probable date of spawning was back-calculated by subtracting the total age (PLD + post-settlement age) of the juvenile fish from the date when the fish was collected. Date of settlement was estimated by adding PLD to the back-calculated spawning date.

\section{Dispersal kernel estimation}


A larval dispersal kernel is a statistical relationship $\rho_{i}(d, k)$ that measures the strength of dispersal occurring between two reefs based on the kernel's functional form $i$, parameterisation $k$ and the distance $d$ between two reefs. Dispersal strength (and therefore the probability of dispersal) was expressed as larval density in proportion to the strength of local retention. Maximum likelihood methods were used to identify the best-fit parameter sets for a series of candidate dispersal kernels: Laplacian, Gaussian, Ribbens and Cauchy functions (the latter is a fat-tailed kernel while the rest are thin-tailed exponential functions) (see ESM, Supplementary Methods). The best shape and optimal parameterisation of these kernels were estimated using both those juveniles in the accepted parentage assignments and the remaining unassigned juveniles. Each kernel and parameterisation combination predicts a relative juvenile composition on each reef comprised by: (1) assignable juveniles from sampled adults; and (2) unassignable juveniles from the unsampled proportion of adults on sampled reefs and all adults from nearby unsampled reefs (i.e., within a radius of $150 \mathrm{~km}$ from the study area) (Fig. 1b). These expected proportions can be used to construct the likelihood of creating the observed sample of juveniles at each sampled reef. The process requires population estimates at all reefs in the system, which were extrapolated from transect survey data on sampled reefs, and by assuming that the typical density of the species on sampled reefs is reflected on the unsampled reefs (see Bode et al. 2016 and ESM, Supplementary Methods).

\section{Results}

\section{Parentage assignments}

From 1978 genotyped juveniles, only 790 had a matching parent in the putative parents sample that complied with the error rate allowed and had positive LOD scores. From the 790, only 72 had a LOD score higher than the threshold (5.1) to accept them as true offspring- 
parent pairs. From these 72 parentage assignments, only 37 juveniles were accepted as being the true offspring of the parents to which they were assigned. Thirty-five of these were assigned to a single parent (mean LOD score of $9.44 \pm 4.68$; range: 5.15 to 31.60 ) while two were each assigned to a parent couple (couple LOD scores of 34.03 and 40.73). The most likely parents were the only assigned parents. The best estimate of total adult population size was 7071 individuals with a high and low estimate of 10,124 and 4018 adults, respectively (ESM, Table S1). The best estimate indicated that $19.6 \%(1387 / 7071)$ of potential parents were sampled. This proportion ranged from 13.7 to $34.5 \%$ if the high and low adult population estimates were used.

\section{Spatial patterns of dispersal}

Thirty-five of the accepted parentage assignments indicated larval dispersal among reefs in Negros Island and between Apo and Negros islands (Fig. 2). Eight of these suggested linkages were among seven NTMRs 9.0 to $41.2 \mathrm{~km}$ apart (Fig. 2a). These included probable larval dispersal from the highly successful Apo NTMR to a much younger NTMR in Negros. Eleven assignments suggested that three NTMRs in Negros, the Apo NTMR and the wellmanaged Apo MPA can supply recruits to fished areas 1.2 to $46.2 \mathrm{~km}$ away. Seven assignments indicated import of larvae from municipal fishing grounds to four NTMRs 11.7 to $47.9 \mathrm{~km}$ away (Fig. 2b). Nine assignments indicated larval dispersal between municipal fishing grounds that were 3.0 to $33.1 \mathrm{~km}$ apart. About half (18/35 or 51\%) of these inferred occurrences of larval dispersal linked municipalities. Inferred incidences of larval dispersal between municipalities that shared a common border were equally as frequent as those between municipalities that were not adjacent to each other. Only two parentage assignments indicated self-recruitment. These occurred near headlands in Negros (Siaton Pt and Bonbonon Pt) and had inferred dispersal distances of 0.2 and $0.6 \mathrm{~km}$ (Fig. 2b). 


\section{Juvenile life history and seasonal patterns of dispersal}

Sagittal otoliths were available for 35 juveniles in the accepted parentage assignments. The mean PLD of this sample was $25.6 \pm 2.3 \mathrm{~d}$ (range: 20 to $30 \mathrm{~d}$ ). This PLD value is shorter than the larval duration of C. vagabundus in other geographic locations, which may be indicative of local adaptation to maximise settlement in a region where reefs are closely spaced (see Leahy et al. 2015 and references therein). Post-settlement life span ranged from 29 to $147 \mathrm{~d}$. Back-calculated spawning dates suggested that spawning and settlement occurred during the two monsoons and two monsoon transition periods between 21 July 2011 and 16 October 2012. Ten out of 11 fish that were spawned during the southwest monsoon had eastward/northeastward inferred dispersal trajectories, which suggested downwind drift (Fig. 3a). Downwind larval transport was also indicated by the inferred westward dispersal of 16 out of 20 fish that were spawned during the northeast monsoon (Fig. 3b). Three of the four fish that were spawned during monsoon transition periods had westward dispersal trajectories, suggesting advection by the Bohol Jet (Fig. 3c).

\section{Estimated potential dispersal kernel}

The Ribbens kernel offered the best fit to the parentage data (Table 1; Fig. 4; ESM, Fig. S2). This kernel predicts that $50 \%$ of larvae would settle within $33 \mathrm{~km}$, or $95 \%$ within $83 \mathrm{~km}$ of parents (if habitat were available). The mean larval dispersal distance calculated from this kernel was $36.5 \mathrm{~km}$ while the standard deviation was estimated to be $44.2 \mathrm{~km}$. Note, however, that these values do not differ considerably from those of the Laplacian and Gaussian kernels (Table 1), suggesting that the specific shape of the dispersal kernel does not alter conclusions about the average distance travelled by larvae.

\section{Discussion}


This study revealed patterns of reef-fish larval dispersal in a region where NTMR networks could play a crucial role in coral-reef conservation and fisheries management over large spatial scales. Most of the accepted parentage assignments suggested larval dispersal among NTMRs and fishing grounds with about half of these connecting the reefs of independent local government units. On the other hand, inferred occurrences of self-recruitment were rare. Seasonal variations in larval dispersal appeared to be related to monsoon-induced surface current reversals notwithstanding the presence of a strongly unidirectional current. The estimated larval dispersal kernel predicts that most larvae could settle within several tens of $\mathrm{km}$ from their parents, which indicates that any of the 23 NTMRs has a reasonable chance of supplying recruits to a good number of NTMRs and fishing grounds within the study area.

The study suffers from three weaknesses. First is the small number of parentage assignments that were detected, despite an intensive sampling effort over a large scale. This was probably due to sampling a low proportion of parents within the study area. However, considerable immigration of recruits from populations outside this area is also plausible given the scale of the estimated larval dispersal kernel (Figs. 1,4). Second is the lack of temporal replication. Larval dispersal patterns were inferred for about one year only. The results should therefore be treated with some caution. Repeated sampling and parentage analysis to determine interannual variability were not feasible due to financial constraints. Third, the study does not provide any insights into population connectivity beyond the first few months of the juvenile stage (i.e., up to adulthood). The fates of recruits are likely to vary across sites given local ecological conditions (Leahy et al. 2015), thus modifying the strength of population connections suggested by larval dispersal. However, determining patterns of full demographic connectivity was beyond the scope of this study.

Despite these deficiencies, several aspects of this work improve the understanding of natural patterns of larval dispersal in reef fish and consequently, probable connectivity patterns and 
their implications for implementing NTMR networks. First, the results contribute to growing evidence showing that mutual replenishment among NTMRs and enhanced larval supply to fished populations may occur within a system of replicated and closely spaced NTMRs encompassing a moderate spatial scale (several tens of $\mathrm{km}$ ). This evidence further substantiates existing recommendations to space NTMRs less than a few tens of km apart to enhance the recruitment subsidy effect (McCook et al. 2009; Fernandes et al. 2012; Green et al. 2015). For example, Green et al. (2015) recommended spacing NTMRs no more than 15 $\mathrm{km}$ apart as a general guideline for designing NTMR networks for reef fish. They further advised spacing NTMRs much less than this distance in countries where NTMRs tend to be small $\left(<1 \mathrm{~km}^{2}\right)$ for the simple reason that small NTMRs would have less larval output than larger ones. Presently, there is very limited empirical evidence for close spacing between NTMRs enhancing the recruitment subsidy effect (Grorud-Colvert et al. 2014) but it is worth pointing out that in heavily fished regions, the enhanced recruitment subsidy effect of NTMRs could be crucial if spawning biomass is too low in surrounding fished areas (Pelc et al. 2010; Russ and Alcala 2010).

Second, the result suggesting that the reef-fish populations are more open than closed (i.e., incidences of dispersal showing potential connectivity far outnumbered self-recruitment) seems to agree with predictions about how larval dispersal and habitat patchiness can influence population openness. Modelling studies by Pinsky et al. (2012) indicate that populations will tend to be more open if habitat spacing is less than twice the standard deviation of the larval dispersal kernel. In the present study, the mean nearest-neighbour distance between reefs and between the NTMRs was one order of magnitude smaller than the standard deviation of the dispersal kernel. High levels of population openness imply that the sustainability of reef-fish populations within the small NTMRs will strongly depend upon connectivity with other NTMRs and fished populations that are close enough (Botsford et al. 
2001; White et al. 2010). Furthermore, the typical size (longest dimension) of the NTMRs was up to two orders of magnitude smaller than the estimated mean larval dispersal distance of the study species or any Indo-Pacific reef-fish species studied to date (reviewed by Green et al. 2015), indicating that the NTMRs are unlikely to sustain themselves through selfseeding (Botsford et al. 2001; White et al. 2010). These inferences further underscore the importance of sufficiently close spacing between small NTMRs. However, theoretical studies also suggest that if small NTMRs only protect a very limited proportion (e.g., much less than 20-30\%) of the total fish population and fishing pressure remains unabated, their populations cannot be sustained because of inadequate replenishment through connectivity (Botsford et al. 2001; White et al. 2010; Hopf et al. 2016).

Third, the study documents a direct correlation between seasonal trends in larval dispersal and current reversals driven by the monsoons. Monsoon wind forcing could be an important driver of reef-fish connectivity patterns in regions closer to the equator, affecting not only larval dispersal but also survival (Abesamis and Russ 2010). However, empirical evidence for monsoon impacts on larval dispersal is rare (Cowen 2006; Pineda et al. 2007). For instance, Saenz-Agudelo et al. (2012) did not detect a relationship between larval dispersal in the damselfish Amphiprion polymnus (a benthic spawner with a PLD of $\sim 12 \mathrm{~d}$ ) and monsoondriven current reversals in a parentage study in Papua New Guinea. They attributed this result mainly to the small spatial scale of their study $(\sim 35 \mathrm{~km})$, arguing that larval behaviour could have had a stronger influence on dispersal than current directionality at this scale. In the present study, the detection of seasonal dispersal trends may have been facilitated by sampling at a larger scale and the mid-water spawning mode and longer larval life of the study species. The seasonal patterns documented here suggest that for some species with relatively long PLDs, recruitment subsidies from NTMRs in monsoonal regions may be more homogenously distributed over large areas on an annual basis, thus potentially benefitting 
stakeholders more evenly in a network. This possibility is more likely for reef-fish species that spawn throughout most of the year at lower latitudes (Claydon et al. 2014; Abesamis et al. 2015) than for those with shorter spawning seasons that may or may not coincide with the monsoons (Hamilton et al. 2011).

Fourth, the results indicate that in some situations, the fisheries management measures implemented by one coastal community (a village or a municipality) may have a greater impact on reef-fish populations outside, as opposed to within, their jurisdiction (also see Almany et al. 2013).That is, returns or feedback in terms of larval supply may be less at smaller scales of management compared to external recruitment subsidies. Here, feedback is likely to be much weaker at the scale of individual NTMRs managed by villages compared to management at the municipal level. On the other hand, feedback could be weaker within a single municipality compared to collaborative management between two or more adjacent municipalities. Weaker feedback emphasises the importance of nested management and cooperation among ecologically connected, but politically separate, management units to harness the recruitment subsidy effect of individual NTMRs more effectively. Collaboration among independent management units is one strategy by which local-scale actions subject to socio-economic constraints can be scaled up to address regional objectives (Mills et al. 2010; Weeks et al. 2014). This strategy has had some success in forming NTMR networks within a broader ecosystem management framework in situations where fisheries management has been delegated to more local levels (Lowry et al. 2009; Horigue et al. 2012, 2016; Weeks et al. 2014). However, weak institutional support at the network level remains a major hurdle (White et al. 2014).

In conclusion, this study validated an integral process in the ecological basis for NTMR networks. The results underscored the importance of, and provide justification for, close spacing between small NTMRs to form a dense and mutually replenishing network. This is 
especially important in regions where large NTMRs are less feasible. The study also highlighted significant challenges for the creation of large-scale NTMR networks in coralreef countries: (1) strengthening coordinated management across political or customary boundaries; and (2) ensuring adequate population connectivity to sustain reef-fish populations. The first is necessitated by a high likelihood of larval dispersal at spatial scales that can encompass independent management units but in the archipelagic setting of many coral-reef countries may also mean dependence of a network on management units outside of this network. The second will require protecting a relatively large fraction of reefs within NTMRs and significantly reducing fishing pressure. These challenges should be addressed with high priority as advocacy for NTMR networks in the developing world continues to grow.

\section{Acknowledgements}

Financial support was provided by the Deutsche Gesellschaft für Internationale Zusammenarbeit (GIZ) ACCCoast Program to RAA, the ARC Centre of Excellence for Coral Reef Studies at JCU to GRR and KAUST baseline research funds to MLB. Collection of samples was permitted by the Department of Agriculture-Bureau of Fisheries and Aquatic Resources (DA-BFAR) in accordance with Philippine laws and regulations (RA 9147; FAO 233) and approved by the JCU animal ethics committee. Prior informed consent and support for this research was given by fisherfolk communities and municipal officials in Negros and the AIPLS Protected Area Management Board. ENRD-Negros Oriental, M. Teves, M.

Barillo, D. Inocencio, R. Tuble, T. Yucor, R. Tubat, M. Pascobello, S. Leahy, A. Bucol, A. Regalado, O. Paderanga, M. Martin, J. Maypa and SU-IEMS provided valuable assistance. G. Almany, H. Harrison, G. Jones and S. Planes are thanked for their support. A. Bucol and D.C. Lou processed the otoliths. Staff at the KAUST Bioscience Core Lab assisted with DNA 
analysis. The authors are grateful to two anonymous reviewers whose comments greatly

improved the paper. RAA dedicates this work to the memory of E.Q. Abesamis.

\section{References}

Abesamis RA, Russ GR (2010) Patterns of recruitment of coral reef fishes in a monsoonal environment. Coral Reefs 29:911-921

Abesamis RA, Jadloc CRL, Russ GR (2015) Varying annual patterns of reproduction in four species of coral reef fish in a monsoonal environment. Mar Biol 162:1993-2006

Alcala AC, Russ GR (2006) No-take marine reserves and reef fisheries management in the Philippines: a new people power revolution. Ambio 35:245-254

Almany GR, Hamilton RJ, Bode M, Matawai M, Potuku T, Saenz-Agudelo P, Planes S, Berumen ML, Rhodes KL, Thorrold SR, Russ GR, Jones GP (2013) Dispersal of grouper larvae drives local resource sharing in a coral reef fishery. Curr Biol 23:626630

Ban NC, Adams VM, Almany GR, Ban S, Cinner JE, McCook LJ, Mills M, Pressey RL, White AW (2011) Designing, implementing and managing marine protected areas: emerging trends and opportunities for coral reef nations. J Exp Mar Bio Ecol 408:2131

Berumen ML, Almany GR, Planes S, Jones GP, Saenz-Agudelo P, Thorrold SR (2012) Persistence of self-recruitment and patterns of larval connectivity in a marine protected area network. Ecol Evol 2:444-452

Bode M, Williamson D, Harrison H, Outram N, Jones GP (2016) Estimating dispersal kernels using genetic parentage data. bioRxiv [doi: 10.1101/044305]

Botsford LW, Hastings A, Gaines SD (2001) Dependence of sustainability on the configuration of marine reserves and larval dispersal distance. Ecol Lett 4:144-150

Burgess SC, Nickols KJ, Griesemer CD, Barnett LAK, Dedrick AG, Satterthwaite EV, Yamane L, Morgan SG, White JW, Botsford LW (2014) Beyond connectivity: how empirical methods can quantify population persistence to improve marine protected area design. Ecol Appl 24:257-270

Claydon JAB, McCormick MI, Jones GP (2014) Multispecies spawning sites for fishes on a low-latitude coral reef: spatial and temporal patterns. J Fish Biol 84:1136-1163

Cook GS, Parnell PE, Levin LA (2014) Population connectivity shifts at high frequency within an open-coast marine protected area network. PLoS One 9:e103654

Cowen RK (2006) Larval dispersal and retention and consequences for population connectivity. In: Sale PF (ed.) Coral reef fishes - dynamics and diversity in a complex ecosystem. Elsevier, London, pp 149-170

D’Aloia CC, Bogdanowicz SM, Francis RK, Majoris JE, Harrison RG, Buston PM (2015) Patterns, causes, and consequences of marine larval dispersal. Proc Natl Acad Sci USA 112:13940-13945

Fernandes L, Green A, Tanzer J, White A, Aliño PM, Jompa J, Lokani P, Soemodinoto A, Knight M, Pomeroy R, Possingham H, Pressey RL (2012) Biophysical principles for designing resilient networks of marine protected areas to integrate fisheries, biodiversity and climate change objectives in the Coral Triangle - final report. The Nature Conservancy for the Coral Triangle Support Partnership, Arlington, TX, USA 
Gaines SD, White C, Carr MH, Palumbi SR (2010) Designing marine reserve networks for both conservation and fisheries management. Proc Natl Acad Sci USA 107:1828618293

Gerber S, Chabrier P, Kremer A (2003) FAMOZ: a software for parentage analysis using dominant, co-dominant and uni-parentally inherited markers. Mol Ecol Notes 3:479481

Gordon AL, Sprintall J, Ffield A (2011) Regional oceanography of the Philippine archipelago. Oceanography 24:14-27

Green AL, Maypa AP, Almany GR, Rhodes KL, Weeks R, Abesamis RA, Gleason MG, Mumby PJ, White AT (2015) Larval dispersal and movement patterns of coral reef fishes, and implications for marine reserve network design. Biol Rev 90:1215-1247

Green A, Smith E, Lipsett-Moore G, Groves G, Peterson N, Sheppard S, Lokani P, Hamilton R, Almany J, Aitsi J, Bualia L (2009) Designing a resilient network of marine protected areas for Kimbe Bay, Papua New Guinea. Oryx 43:488-498

Grorud-Colvert K, Claudet J, Tissot BN, Caselle JE, Carr MH, Day JC, Friedlander AM, Lester SE, Lison de Loma T, Malone D, Walsh WJ (2014) Marine protected area networks: assessing whether the whole is greater than the sum of its parts. PLoS One 9:e102298

Hamilton RJ, Potuku T, Montambault J (2011) Community-based conservation results in the recovery of reef fish spawning aggregations in the Coral Triangle. Biol Conserv 144:1850-1858

Harrison HB, Williamson DH, Evans RD, Almany GR, Thorrold SR, Russ GR, Feldheim KA, van Herwerden L, Planes S, Srinivasan M, Berumen ML, Jones GP (2012) Larval export from marine reserves and the recruitment benefit for fish and fisheries. Curr Biol 22:1023-1028

Harrison HB, Saenz-Agudelo P, Planes S, Jones GP, Berumen ML (2013) Relative accuracy of three common methods of parentage analysis in natural populations. Mol Ecol 22:1158-1170

Honda K, Nakamura Y, Nakaoka M, Uy WH, Fortes MD (2013) Habitat use by fishes in coral reefs, seagrass beds and mangrove habitats in the Philippines. PLoS One 8:e65735

Hopf JK, Jones GP, Williamson DH, Connolly SR (2016) Fishery consequences of marine reserves: short-term pain for longer-term gain. Ecol Appl 26:818-829

Horigue V, Aliño PM, White AT, Pressey RL (2012) Marine protected area networks in the Philippines: trends and challenges for establishment and governance. Ocean Coast Manag 64:15-26

Horigue V, Pressey RL, Mills M, Brotánková J, Cabral R, Andréfouët S (2016) Benefits and challenges of scaling up expansion of marine protected area networks in the Verde Island Passage, central Philippines. PLoS One10:e0135789

Jones GP, Almany GR, Russ GR, Sale PF, Steneck RS, van Oppen MJH, Willis BL (2009) Larval retention and connectivity among populations of corals and reef fishes: history, advances and challenges. Coral Reefs 28:307-325

Leahy SM, Russ GR, Abesamis RA (2015) Pelagic larval duration and settlement size of a reef fish are spatially consistent, but post-settlement growth varies at the reef scale. Coral Reefs 34:1283-1296

Leis JM (1989) Larval biology of butterflyfishes (Pisces, Chaetodontidae): what do we really know? Environ Biol Fishes 25:87-100

Lester SE, Ruttenberg BI (2005) The relationship between pelagic larval duration and range size in tropical reef fishes: a synthetic analysis. Proc R Soc Lond B Biol Sci 272:585591 
Lowry GK, White AT, Christie P (2009) Scaling up to networks of marine protected areas in the Philippines: biophysical, legal, institutional and social considerations. Coast Manage 37:274-290

McCook LJ, Almany GR, Berumen ML, Day JC, Green AL, Jones GP, Leis JM, Planes S, Russ GR, Sale PF, Thorrold SR (2009) Management under uncertainty: guide-lines for incorporating connectivity into the protection of coral reefs. Coral Reefs 28:353366

Mills M, Pressey RL, Weeks R, Foale S, Ban NC (2010) A mismatch of scales: challenges in planning for implementation of marine protected areas in the Coral Triangle. Conserv Lett 3:291-303

Mora C, Andréfouët S, Costello MJ, Kranenburg C, Rollo A, Veron J, Gaston KJ, Myers RA (2006) Coral reefs and the global network of marine protected areas. Science 312:1750-1751

Nañola CLJr, Aliño PM, Carpenter KC (2011) Exploitation-related reef fish species richness depletion in the epicenter of marine biodiversity. Environ Biol Fishes 90:405-420

Newton K, Côté IM, Pilling GM, Jennings S, Dulvy NK (2007) Current and future sustainability of island coral reef fisheries. Curr Biol 17:655-658

Pelc RA, Warner RR, Gaines SD, Paris CB (2010) Detecting larval export from marine reserves. Proc Natl Acad Sci USA 107:18266-18271

Pineda J, Hare JA, Sponaugle S (2007) Larval transport and dispersal in the coastal ocean and consequences for population connectivity. Oceanography 20:22-39

Pinsky ML, Montes HR Jr, Palumbi SR (2010) Using isolation by distance and effective density to estimate dispersal scales in anemonefish. Evolution 64:2688-2700

Pinsky ML, Palumbi SR, Andréfouët S, Purkis SJ (2012) Open and closed seascapes: where does habitat patchiness create populations with high fractions of self-recruitment? Ecol Appl 22:1257-1267

Pratchett MS, Berumen ML, Marnane MJ, Eagle JV, Pratchett DJ (2008) Habitat associations of juvenile versus adult butterflyfishes. Coral Reefs 27:541-551

Pusack TJ, Christie MR, Johnson DW, Stallings CD, Hixon MA (2014) Spatial and temporal patterns of larval dispersal in a coral-reef fish metapopulation: evidence of variable reproductive success. Mol Ecol 23:3396-3408

Russ GR, Alcala AC (2010) Decadal scale rebuilding of predator biomass in Philippine marine reserves. Oecologia 163:1103-1106

Saenz-Agudelo P, Jones GP, Thorrold SR, Planes S (2011) Connectivity dominates larval replenishment in a coastal reef fish metapopulation. Proc R Soc Lond B Biol Sci 278:2954-2961

Saenz-Agudelo P, Jones GP, Thorrold SR, Planes S (2012) Patterns and persistence of larval retention and connectivity in a marine fish metapopulation. Mol Ecol 21:4695-4705

Sale PF, Cowen RK, Danilowicz BS, Jones GP, Kritzer JP, Lindeman KC, Planes S, Polunin NVC, Russ GR, Sadovy YJ, Steneck RS (2005) Critical science gaps impede use of no-take fishery reserves. Trends Ecol Evol 20:74-80

Steneck RS, Paris CB, Arnold SN, Ablan-Lagman MC, Alcala AC, Butler MJ, McCook LJ, Russ GR, Sale PF (2009) Thinking and managing outside the box: coalescing connectivity networks to build region-wide resilience in coral reef ecosystems. Coral Reefs 28:367-378

Tanaka N (1992) Pair territory and diurnal migration of the vagabond butterflyfish Chaetodon vagabundus. Galaxea 11:66

Thresher RE (1984) Reproduction in reef fishes. T.F.H. Publications, New Jersey

Wang B, Liu J, Kim HJ, Webster PJ, Yim SY (2012) Recent change of the global monsoon precipitation (1979-2008). Clim Dyn 39:1123-1135 
Weeks R, Russ GR, Alcala AC, White AT (2010) Effectiveness of marine protected areas in the Philippines for biodiversity conservation. Conserv Biol 24:531-540

Weeks R, Aliño PM, Atkinson S, Beldia P, Binson A, Campos WL, Djohani R, Green AL, Hamilton R, Horigue V, Jumin R, Kalimk K, Kasasiahl K, Keresekam J, Klein C, Laroya L, Magupin S, Masike B, Mohan C, Pinto RMDS, Vave-Karamui A, Villanoy C, Welly M, White AT (2014) Developing marine protected area networks in the Coral Triangle: good practices for expanding the Coral Triangle marine protected area system. Coast Manage 42:183-205

White AT, Aliño PM, Cros A, Fatan NA, Green AL, Teoh SJ, Laroya L, Peterson N, Tan S, Tighe S, Venegas-Li R (2014) Marine protected areas in the Coral Triangle: progress, issues, and options. Coast Manage 42:87-106

White JW, Botsford LW, Hastings A, Largier JL (2010) Population persistence in marine reserve networks: incorporating spatial heterogeneities in larval dispersal. Mar Ecol Prog Ser 398:49-67

Williamson DH, Harrison HB, Almany GR, Berumen ML, Bode M, Bonin MC, Choukroun S, Doherty PJ, Frisch AJ, Saenz-Agudelo P, Jones GP (2016) Large-scale, multidirectional larval connectivity among coral reef populations in the Great Barrier Reef Marine Park. Mol Ecol 25:6039-6054

Wyrtki K (1961) Physical oceanography of the Southeast Asian waters. Scripps Institution of Oceanography, University of California, La Jolla, CA, USA 


\section{Figures}

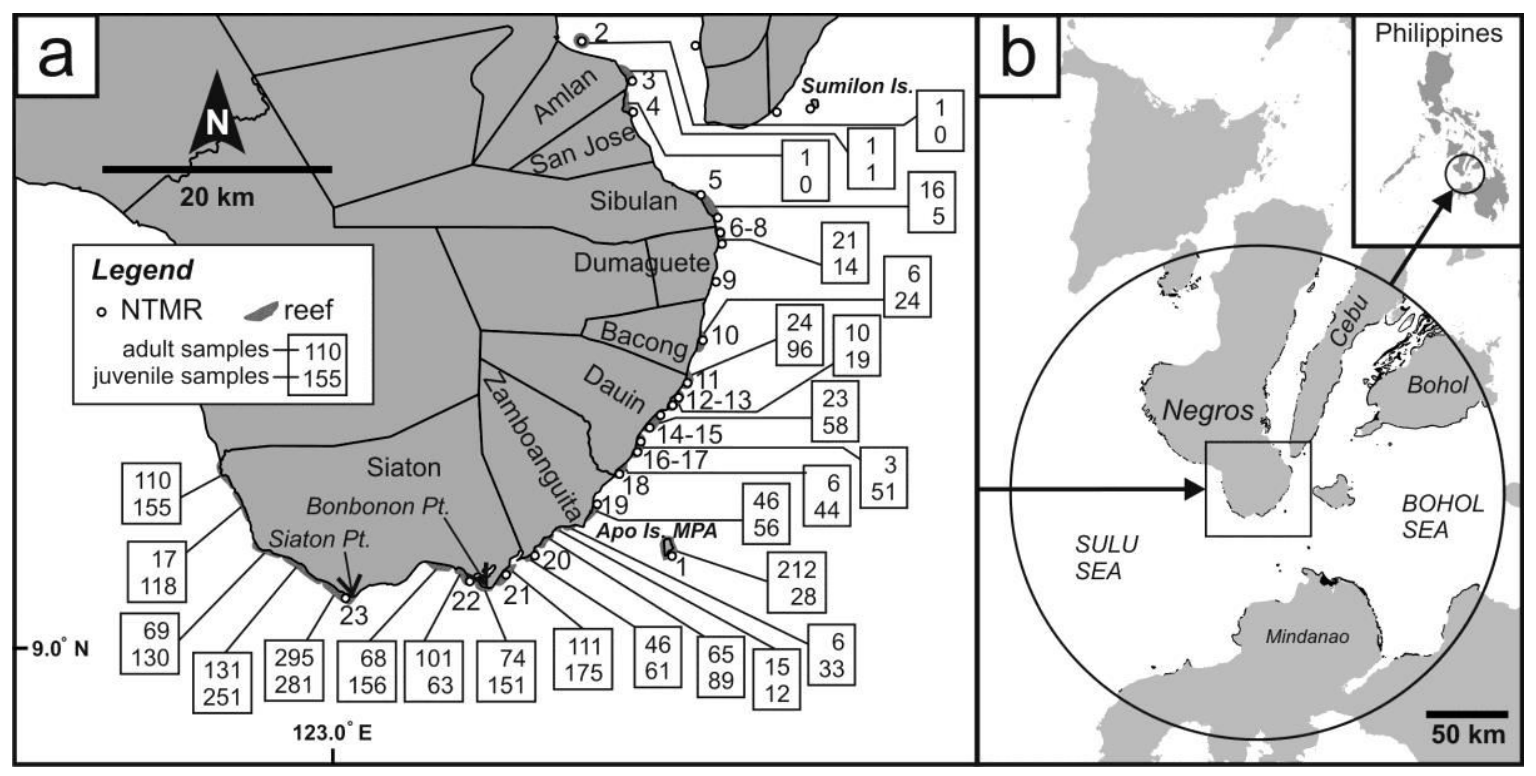

Fig. 1 Study area (a) showing the location of NTMRs (numbered 1 to 23), the 26 sampled reefs and the sample sizes of adult and juvenile Chaetodon vagabundus per reef; greater study region (b) showing reefs (black) within a radius of $150 \mathrm{~km}$ (encircled) from the study area 

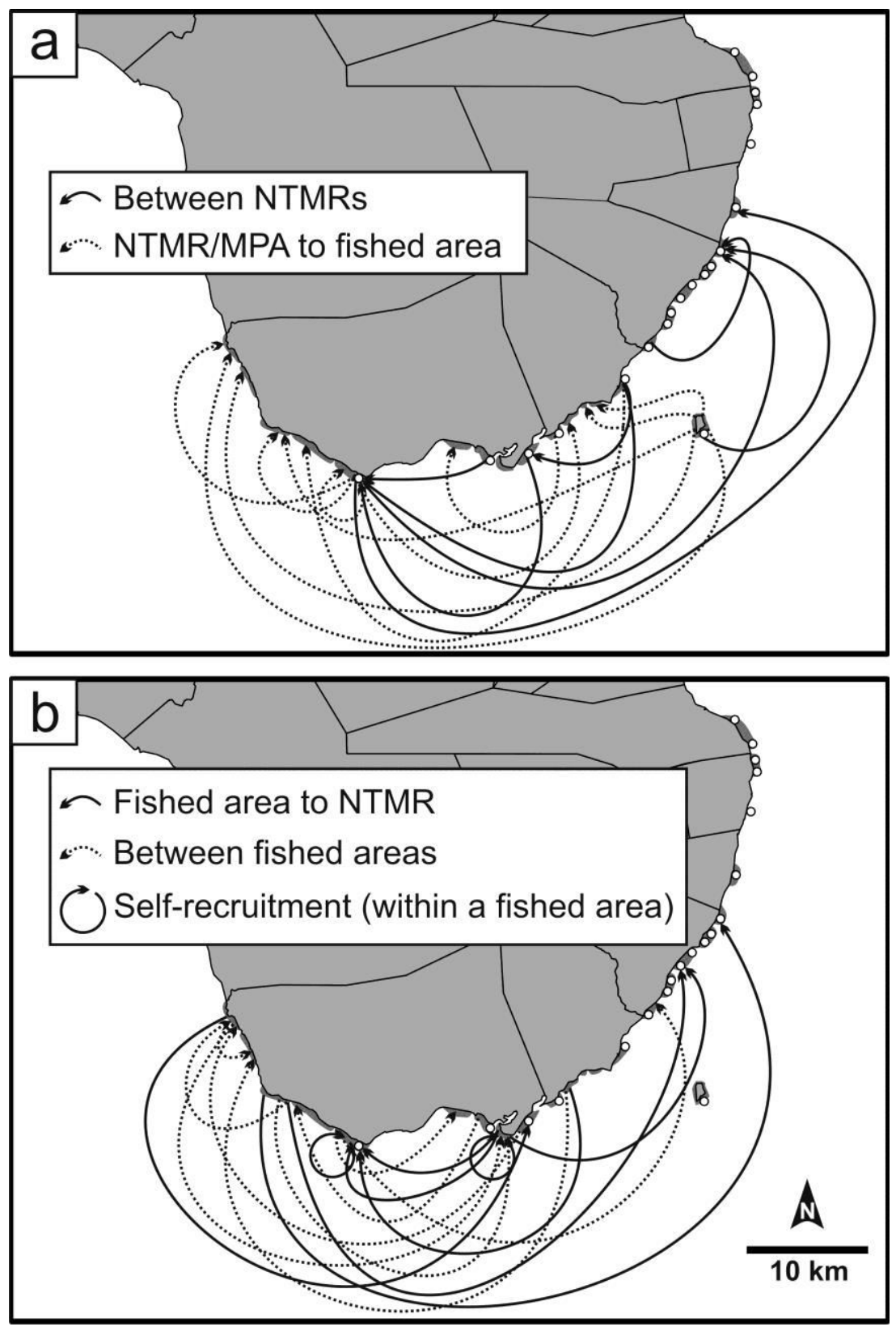

Fig. 2 Inferred patterns of larval dispersal from NTMRs (a) and from fished areas (b) 

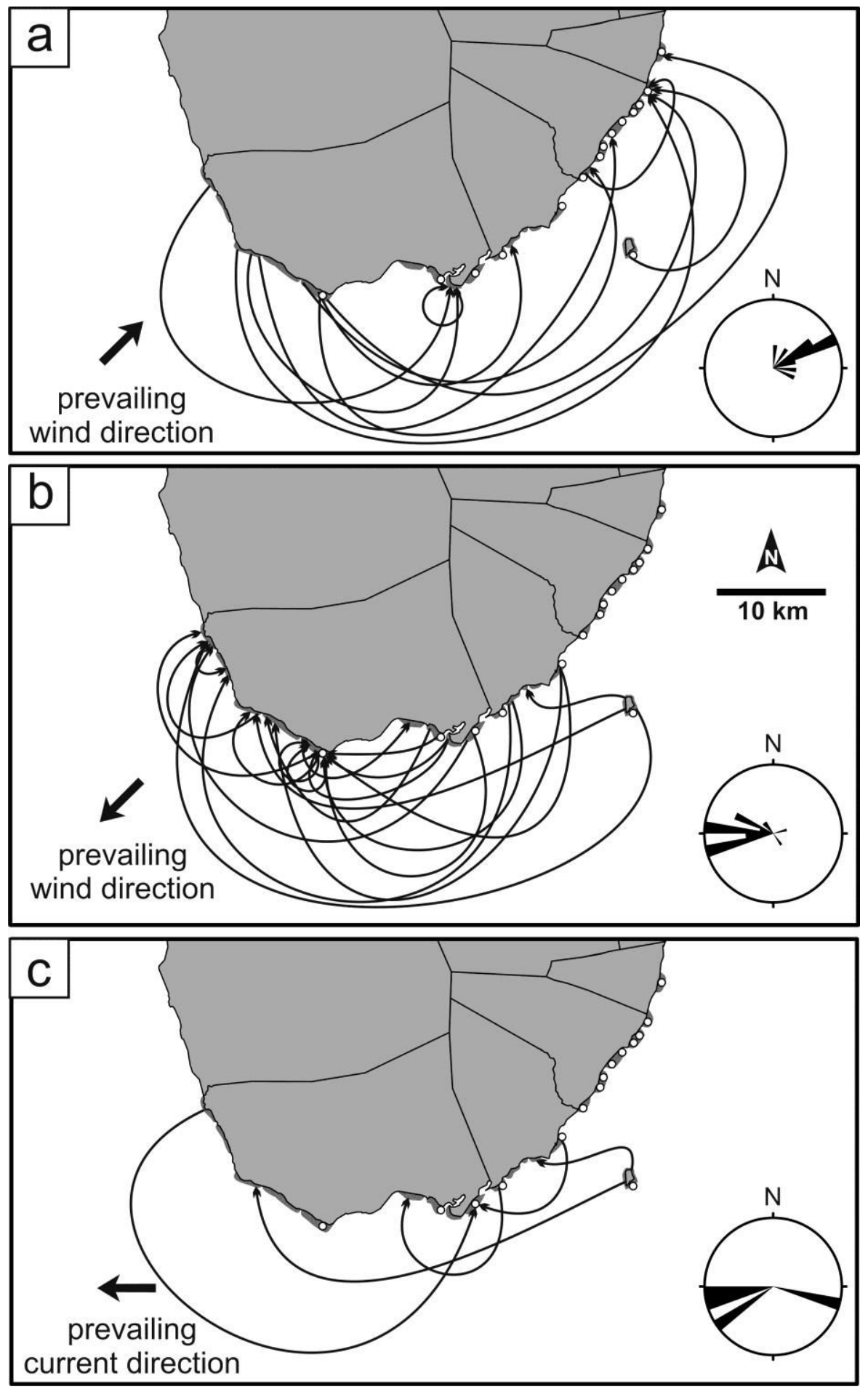

Fig. 3 Inferred patterns of larval dispersal for juvenile fish that were spawned during the southwest monsoon (a), the northeast monsoon (b) and the monsoon transition periods (c). The angle histogram on the lower right of each panel summarizes the directions of inferred dispersal trajectories per season 


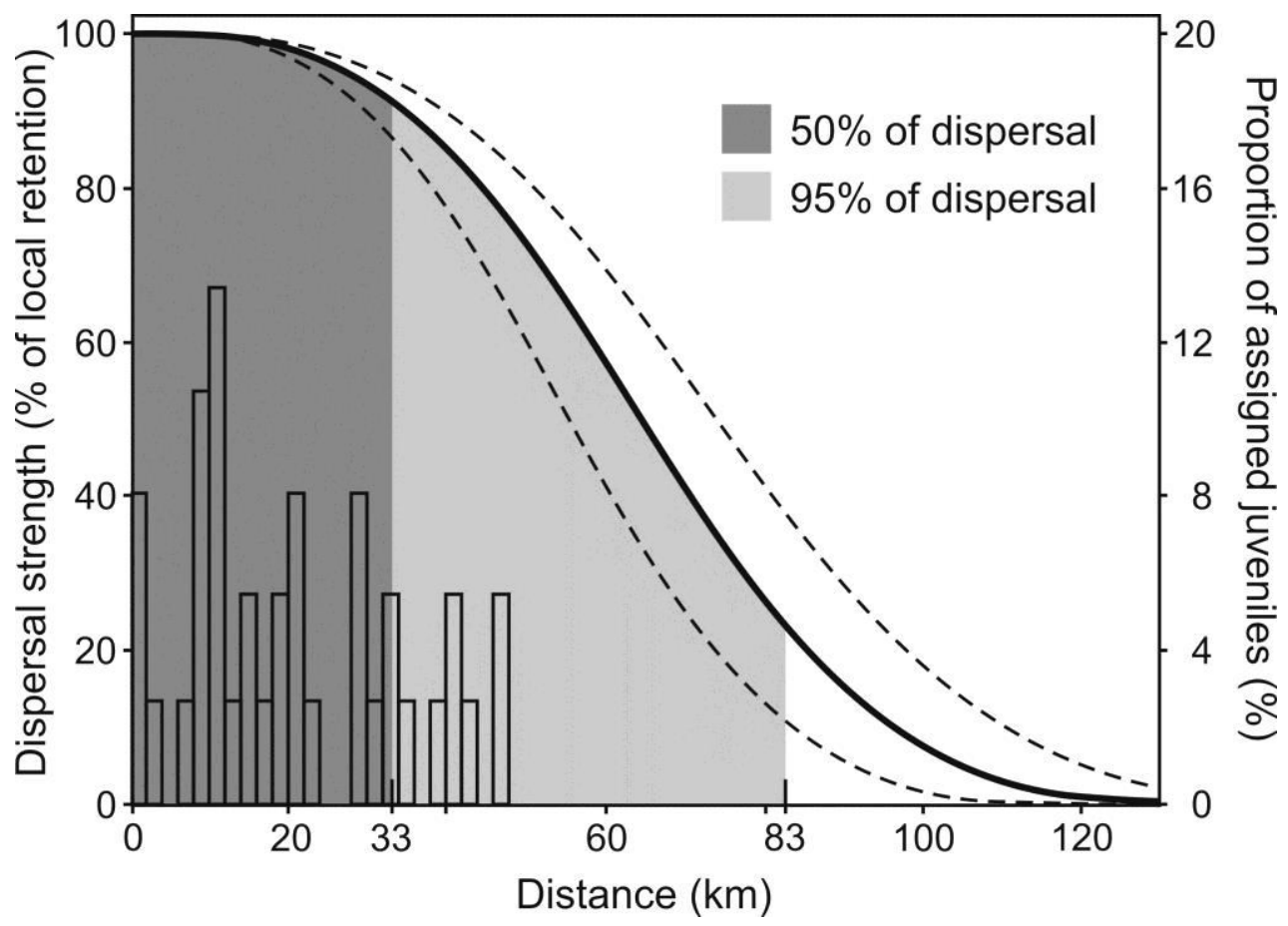

Fig. 4 Potential larval dispersal kernel (solid black line) estimated from parentage data and estimates of the proportions of unsampled parents to account for unassigned juveniles. The best-fit model is a Ribbens kernel (Table 1). Dashed lines denote the 95\% confidence intervals of the fit. Dispersal strength (and therefore the likelihood of dispersal) is reported as larval density in proportion to the strength of local retention (left y-axis). Shaded regions indicate the proportion of larval dispersal that could settle at increasing distances from the natal reef if suitable habitat were available. The histogram shows the frequency of dispersal distances (in 2-km intervals) of the 37 juveniles in accepted parentage assignments (right $y$ axis) 
Table 1. Model fit parameters for four candidate larval dispersal kernels $[\ln (k)]$.

\begin{tabular}{|l|c|c|c|c|}
\hline $\begin{array}{l}\text { Dispersal } \\
\text { kernel }\end{array}$ & $\begin{array}{l}\text { Best-fit kernel } \\
\text { parameter }\end{array}$ & $\begin{array}{l}\text { Likelihood of the } \\
\text { best-fit parameter }\end{array}$ & $\begin{array}{l}\text { Mean dispersal } \\
\text { distance }(\mathrm{km})\end{array}$ & $\begin{array}{l}\text { Standard } \\
\text { deviation }(\mathrm{km})\end{array}$ \\
\hline Ribbens & -12.8 & 285.3 & 36.5 & 44.2 \\
\hline Gaussian & -8.3 & 285.9 & 34.8 & 43.7 \\
\hline Laplacian & -3.5 & 289.8 & 32.4 & 45.8 \\
\hline Cauchy & 3.1 & 295.9 & $\mathrm{n} / \mathrm{a}$ & $\mathrm{n} / \mathrm{a}$ \\
\hline
\end{tabular}

